\title{
Misuse of inhalers among COPD patients in a community hospital in Taiwan
}

This article was published in the following Dove Press journal:

International Journal of COPD

\author{
Chi-Yen Liang' \\ Yi-Jen Chen' \\ Shew-Meei Sheu ${ }^{2}$ \\ Ching-Fang Tsai ${ }^{2}$ \\ Wei Chen'
}

'Division of Pulmonary and Critical Care Medicine, Ditmanson Medical Foundation Chia-Yi Christian Hospital, Chia-Yi City, Taiwan; ${ }^{2}$ Department of Medical Research, Ditmanson Medical Foundation Chia-Yi Christian Hospital, Chia-Yi City, Taiwan
Correspondence: Wei Chen

Division of Pulmonary and Critical Care

Medicine, Ditmanson Medical Foundation

Chia-Yi Christian Hospital, Number 539,

Zhongxiao Road, East District, Chia-Yi

City, 60002, Taiwan

Tel +886 5276504 I

Fax +886 527745 I I

Email peteralfa2004@yahoo.com.tw
Purpose: Respiratory inhalers, which directly deliver medication to the airway, are important for controlling symptoms and preventing exacerbations of chronic obstructive pulmonary disease (COPD). The inhaler misuse rate of patients with COPD in Taiwan is unclear. In this study, the inhaler techniques and patient characteristics associated with incorrect inhaler techniques among patients with COPD were evaluated.

Patients and methods: This cross-sectional study enrolled 298 patients with COPD (mean age 72.10 years) who used at least one inhaler device. The following five types of inhalers were included: metered-dose inhaler (MDI) with spacer, Diskus ${ }^{\circledR}$, Turbuhaler ${ }^{\circledR}$, Respimat $^{\mathbb{R}}$, and Breezhaler ${ }^{\circledR}$. The inhaler technique was evaluated step by step. Misuse of an individual inhaler was defined as an error in at least one step. The sociodemographic characteristics, vision, hearing ability, type and number of inhalers, and inhaler-related knowledge of these patients were recorded.

Results: The misuse rates of the five types of inhalers ranged from $65.00 \%$ to $87.89 \%$. The Respimat inhaler was the most likely to be assembled incorrectly. The steps that were most commonly performed incorrectly were "breathing out fully" and "holding breath". In the logistic regression analysis, poor hearing was related to misuse of the MDI with spacer (adjusted odds ratio [aOR] 9.85; 95\% CI 1.40-69.30); the number of acute exacerbations was related to misuse of Breezhaler (aOR 4.07; 95\% CI 1.50-11.08). Incorrect inhaler-related knowledge was significantly associated with misuse in handling the MDI with spacer (aOR 9.58; 95\% CI 2.14-42.80), Respimat (aOR 5.14; 95\% CI 2.07-12.76), and Breezhaler (aOR 6.98; 95\% CI 1.95-25.08).

Conclusion: The misuse rates were high for all five types of inhaler. Poor hearing and the number of acute exacerbations were device-specific factors related to the misuse of inhalers. Inhaler-related knowledge was significantly associated with misuse, emphasizing the importance of inhaler education.

Keywords: misuse, inhaler, chronic obstructive pulmonary disease

\section{Introduction}

Chronic obstructive pulmonary disease (COPD) causes significant morbidity and mortality worldwide in the elderly and is estimated to become the third highest cause of death globally by $2020 .^{1,2}$ The mortality trend of patients with COPD in Taiwan has increased since 2009 in both genders, but especially in males. ${ }^{3}$ The COPD age-adjusted mortality of males increased from 51.89 to 59.67 per 100,000 persons from 2010 to $2012 .^{3}$ Good disease and symptom control in patients with COPD can improve the health-related quality of life and reduce the national economic burden.

Respiratory inhalers are commonly used to deliver long-acting bronchodilators to control symptoms and prevent exacerbations in patients with COPD. ${ }^{4}$ Moreover, respiratory inhalers provide the advantage of targeted drug delivery to the airways, 
which can reduce the occurrence of systemic adverse reactions. Previous studies have shown that 4\%-94\% of patients use their inhalers inappropriately. ${ }^{5,6}$ Poor inhaler technique may decrease the dosage of medicines and affect symptom management. ${ }^{7,8}$ Risk factors for inhaler misuse include older age,${ }^{9}$ the use of multiple inhalers, ${ }^{10}$ and low health literacy. ${ }^{11}$ However, the rate and risk factors of inhaler misuse in Taiwanese patients with COPD is unclear. Therefore, this baseline examination may help to establish strategies to improve inhaler therapy.

Previously, we found that patients with COPD and osteoporosis had worse health-related quality of life. ${ }^{12}$ In this study, we enrolled outpatients with COPD who were referred to the chest clinic of a community hospital and evaluated their inhaler techniques and the patient characteristics associated with incorrect inhaler techniques.

\section{Material and methods}

\section{Study participants and design}

This study was conducted between January 2013 and October 2014 at the outpatient department of the Division of Pulmonary and Critical Care Medicine, Ditmanson Medical Foundation Chia-Yi Christian Hospital, which is a 1,000-bed community-based teaching hospital in Chiayi, Taiwan. Potential participants were male and female outpatients with a diagnosis of COPD and $\geq 40$ years old. The potential participants were required to meet the inclusion and exclusion criteria. Patients who met the screening criteria and agreed to sign the informed consent form became study participants. The inclusion criterion was the use of at least one inhaler device. Exclusion criteria included a diagnosis of dementia or a history of bronchial asthma or other structural lung diseases (ie, lung cancer, bronchiectasis, or fibrotic lung). ${ }^{12}$ This cross-sectional study was approved by the Institutional Review Board of the Ditmanson Medical Foundation Chia-Yi Christian Hospital, Taiwan.

\section{Checklists used to assess correct inhaler technique}

The inhaler technique was evaluated by using detailed checklists. The checklists for each of the five inhaler types were developed according to the manufacturers' recommendations and reports in the published literature. ${ }^{13-15}$ The five inhaler types were: 1) a metered-dose inhaler (MDI) with spacer: Alvesco (3M Health Care Limited, Loughborough, Leicestershire, UK), Foster (Chiesi Farmaceutici S.p.A, Parma, EmiliaRomagna, Italy), and Seretide evohaler (Glaxo Wellcome Production, Évreux, Normandy, France); 2) Diskus ${ }^{\circledR}$ : Seretide accuhaler (Glaxo Wellcome Production, Évreux, Normandy, France); 3) Turbuhaler $^{\circledR}$ : Symbicort (AstraZeneca AB, Södertälje, Södermanland, Sweden); 4) Respimat ${ }^{\circledR}$ : Spiriva (Boehringer Ingelheim Pharma GmbH \& Co. KG, Ingelheim am Rhein, Rhineland-Palatinate, Germany); and 5) Breezhaler ${ }^{\circledR}$ : Onbrez (Novartis Pharma Stein AG, Stein, Aargau, Switzerland). Using a spacer can help patients to easily seal their lips and inhale the drug. The eight steps of inhaler use that we evaluated were: 1) assemble the inhaler; 2) hold the inhaler correctly; 3) breathe out fully; 4) seal lips around the mouthpiece; 5) press down the inhaler; 6) press for the number of puffs specified; 7) inhalation timing; and 8) hold breath. A well-trained case manager was assigned to evaluate the step-by-step accuracy of inhaler use. When examining the inhaler technique, misuse of an individual inhaler was defined as an error in at least one step.

\section{Study parameters}

Sociodemographic characteristics, including the patient's age, gender, education level, type and number of inhalers, and inhaler-related knowledge, were recorded using questionnaires. Inhaler-related knowledge included three items: the inhaler dosage; the time period during which the inhaler could be used; and washing the mouth to prevent ulceration, which was based on the instructions from the manufacturer of each inhaler. Incorrect inhaler-related knowledge was defined as the occurrence of an error in any one of the three items. Hearing ability and vision were classified into two subgroups (good and poor). The poor vision subgroup included patients who needed the case manager to read the questionnaires and write down the answers. Patients with good vision could read the questionnaires and answer independently. The font size used in the questionnaire was 14. Poor hearing ability was defined as a patient needing the case manager to speak loudly during conversation. The number of acute exacerbations in the preceding 3 months was reviewed from the medical records of the individuals. The definition of acute exacerbation was a change in the regular medication of patients who visited the outpatient clinic or referral for hospitalization. ${ }^{16}$

\section{Statistical analysis}

Differences in patient characteristics between the pass and misuse groups for the different inhalers was tested using the Student's $t$-test and chi-square test. The crude and adjusted odds ratio (OR) and 95\% confidence intervals (CIs) were calculated using a logistic regression model to investigate the associations of the patient characteristics with incorrect inhaler use. All of the analyses were conducted using SPSS 
software, version 21, of the SPSS System for Windows (IBM Corporation, Somers, NY, USA). Statistical significance was set at a two-tailed $p$-value $<0.05$.

\section{Results}

\section{Patient demographics}

We enrolled 298 patients in this study (Table 1). The mean age of the patients was 72.10 years. A majority of the patients were male $(284,95.30 \%)$ and had education levels of less than junior high school $(212,71.14 \%)$. The numbers of patients using MDI with spacer, Diskus, Turbuhaler, Respimat, and Breezhaler were 79 (26.51\%), 20 (6.71\%), 21 (7.05\%), 223 (74.83\%), and 100 (33.56\%), respectively. Additionally, $45.30 \%$ of the patients used two or more inhalers. The average time duration the patients had used their inhalers was $9.91 \pm 13.68$ months.

Table I Demographic characteristics of patients $(\mathrm{N}=298)$

\begin{tabular}{|c|c|c|}
\hline & $\mathbf{N}$ & $\%$ \\
\hline Age, years (mean $\pm S D)$ & \multicolumn{2}{|c|}{$72.10 \pm 8.98$} \\
\hline$<60$ & 22 & 7.38 \\
\hline $60-69$ & 82 & 27.52 \\
\hline$\geq 70$ & 194 & 65.10 \\
\hline \multicolumn{3}{|l|}{ Gender } \\
\hline Male & 284 & 95.30 \\
\hline Female & 14 & 4.70 \\
\hline BMI, $\mathrm{kg} / \mathrm{m}^{2}($ mean $\pm \mathrm{SD})$ & \multicolumn{2}{|c|}{$23.64 \pm 3.98$} \\
\hline \multicolumn{3}{|l|}{ Education } \\
\hline Illiterate and elementary school & 212 & 71.14 \\
\hline Higher than junior high school & 86 & 28.86 \\
\hline \multicolumn{3}{|l|}{ Hearing } \\
\hline Good & 195 & 65.44 \\
\hline Poor & 103 & 34.56 \\
\hline \multicolumn{3}{|l|}{ Eyesight } \\
\hline Good & 116 & 38.93 \\
\hline Poor & 182 & 61.07 \\
\hline \multicolumn{3}{|l|}{ Number of inhalers used } \\
\hline$<2$ & 163 & 54.70 \\
\hline$\geq 2$ & 135 & 45.30 \\
\hline Duration of inhaler use, months (mean $\pm S D$ ) & \multicolumn{2}{|c|}{$9.91 \pm 13.68$} \\
\hline \multicolumn{3}{|l|}{ Type of inhalers } \\
\hline MDI with spacer & 79 & 26.51 \\
\hline Diskus $^{\circledast}$ & 20 & 6.71 \\
\hline Turbuhaler $^{\circledast}$ & 21 & 7.05 \\
\hline Respimat $^{\circledR}$ & 223 & 74.83 \\
\hline Breezhaler $^{\circledR}$ & 100 & 33.56 \\
\hline
\end{tabular}

Note: All data are presented as $\mathrm{n}(\%)$ unless otherwise indicated. Abbreviations: BMI, body mass index; MDI, metered-dose inhaler.

\section{Misuse rates for respiratory inhalers}

The misuse rates for the five different types of inhalers ranged from $65.00 \%$ (Breezhaler) to $87.89 \%$ (Respimat). No significant differences were found in age, gender, body mass index (BMI), education level, and vision between the pass and misuse groups for the five inhaler types (Table 2). Patients with poor hearing were more likely to use the MDI with spacer incorrectly. Higher proportions of patients in the misuse groups for the MDI with spacer, Turbuhaler, Respimat, and Breezhaler consistently presented incorrect inhaler-related knowledge as compared to the proportions of patients in the pass groups $(p<0.05)$.

The correct and incorrect frequencies for each step of the five inhalers are presented in Table 3. The incorrect rate for the step "assemble the inhaler" was especially high in patients using Respimat (62.78\%), compared to patients using the other inhalers $(0.00 \%-18.99 \%)$. Across all of the inhaler types, the step most likely to be performed incorrectly was "breathing out fully" (58.00\%-80.95\%). Further, the step "holding breath" showed a relatively high rate of error among patients using the five types of inhalers $(29.00 \%-47.62 \%)$. For the other steps, the frequency of incorrect performance ranged from $0.00 \%$ to $22.78 \%$ of the patients.

\section{Patient characteristics related to misuse of inhalers}

Age, gender, BMI, education level, and vision were not related to misuse across the five types of inhalers (Table 4). However, incorrect inhaler-related knowledge was significantly associated with patients misusing three inhalers: the MDI with spacer (adjusted odds ratio [aOR] 9.58; 95\% CI 2.14-42.80), Respimat (aOR 5.14; 95\% CI 2.07-12.76), and Breezhaler (aOR 6.98; 95\% CI 1.95-25.08). When handling the MDI with spacer, patients with poor hearing exhibited increased misuse as compared with patients with good hearing (aOR 9.85; 95\% CI 1.40-69.30). Additionally, misuse in handling the Breezhaler increased the number of acute exacerbations (aOR 4.07; 95\% CI 1.50-11.08).

\section{Discussion}

A national epidemiological survey of patients with COPD in Taiwan revealed that patients with COPD defined by a clinical diagnosis were mostly $>50$ years. ${ }^{17}$ In the present study, the 298 patients with COPD enrolled from a regional hospital had an average age of 72.10 years. The high misuse rates of the five inhalers ranged from $65.00 \%$ to $87.89 \%$. The Respimat inhaler was more likely to be assembled incorrectly than the other inhalers. Across all of the inhalers, the steps 


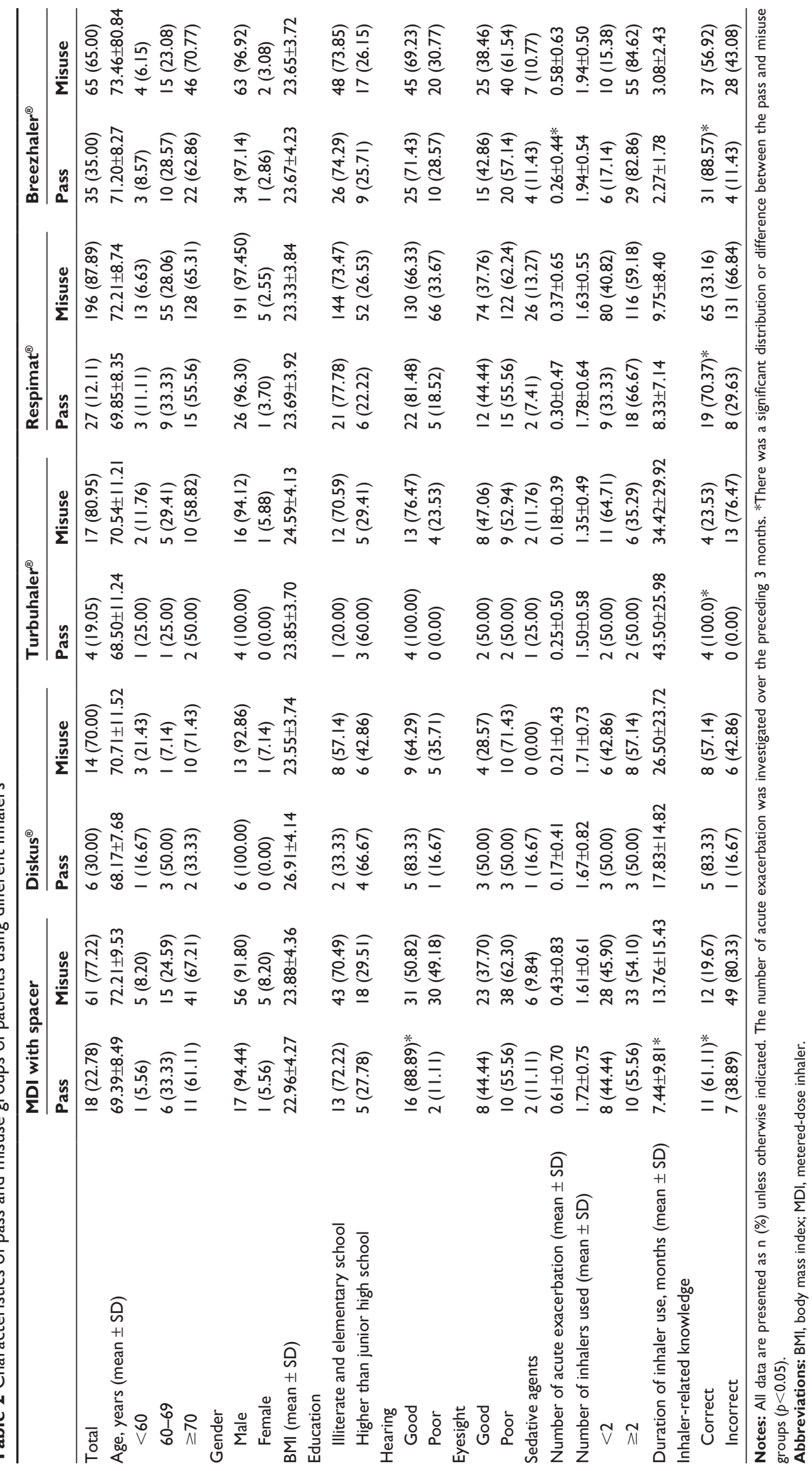


Table 3 Misuse rates of patients performing each step for the five inhaler types

\begin{tabular}{|c|c|c|c|c|c|}
\hline Steps & $\begin{array}{l}\text { MDI with } \\
\text { spacer }\end{array}$ & Diskus $^{\circledR}$ & Turbuhaler $^{\circledR}$ & Respimat $^{\circledR}$ & Breezhaler $^{B}$ \\
\hline \multicolumn{6}{|c|}{ Assembling the inhaler } \\
\hline Yes & $64(81.01)$ & $20(100.00)$ & $19(98.48)$ & $83(37.22)$ & $89(89.00)$ \\
\hline No & $15(18.99)$ & $0(0.00)$ & $2(9.52)$ & $140(62.78)$ & II (II.00) \\
\hline \multicolumn{6}{|c|}{ Holding the inhaler correctly } \\
\hline Yes & $76(96.20)$ & $19(95.00)$ & $21(100.00)$ & $208(93.27)$ & $99(99.00)$ \\
\hline No & $3(3.80)$ & I $(5.00)$ & $0(0.00)$ & $15(6.73)$ & I $(1.00)$ \\
\hline \multicolumn{6}{|l|}{ Breathing out fully } \\
\hline Yes & $27(34.18)$ & $6(30.00)$ & $4(19.05)$ & $70(31.39)$ & $42(42.00)$ \\
\hline No & $52(68.82)$ & $14(70.00)$ & $17(80.95)$ & I53 (68.6I) & $58(58.00)$ \\
\hline \multicolumn{6}{|c|}{ Sealing lips around the mouthpiece } \\
\hline Yes & $70(88.61)$ & $19(95.00)$ & $19(90.48)$ & $187(83.86)$ & $99(99.00)$ \\
\hline No & $9(11.39)$ & I (5.00) & $2(9.52)$ & $36(16.14)$ & I (I.00) \\
\hline \multicolumn{6}{|c|}{ Pressing down the inhaler } \\
\hline Yes & $78(98.73)$ & - & - & $218(97.76)$ & $100(100.00)$ \\
\hline No & $\mathrm{I}(\mathrm{I} .27)$ & - & - & $5(2.24)$ & $0(0.00)$ \\
\hline Not applicable & - & $20(100.00)$ & $21(100.00)$ & - & - \\
\hline \multicolumn{6}{|c|}{ Press for the number of puffs specified } \\
\hline Correct & $67(84.8 I)$ & - & - & $200(89.69)$ & - \\
\hline Incorrect & $12(15.19)$ & - & - & $23(|0.3|)$ & - \\
\hline Not applicable & - & $20(100.00)$ & $21(100.00)$ & - & $100(100.00)$ \\
\hline \multicolumn{6}{|l|}{ Inhalation timing } \\
\hline Adequate & $6 \mathrm{I}(77.22)$ & - & - & $191(85.65)$ & - \\
\hline Inadequate & $18(22.78)$ & - & - & $32(14.35)$ & - \\
\hline Not applicable & - & $20(100.00)$ & $21(100.00)$ & - & $100(100.00)$ \\
\hline \multicolumn{6}{|l|}{ Holding breath } \\
\hline Yes & $48(60.76)$ & $13(65.00)$ & II (52.38) & $130(58.30)$ & $71(71.00)$ \\
\hline No & $31(39.24)$ & $7(35.00)$ & $10(47.62)$ & $93(41.70)$ & $29(29.00)$ \\
\hline
\end{tabular}

Notes: All data are presented as the number (\%) of patients undertaking the uncorrected step compared to the total number of observations. -, not applicable to the device. Abbreviation: MDI, metered-dose inhaler.

that were most likely to be performed incorrectly were "breathing out fully" and "holding breath." Incorrect inhalerrelated knowledge was significantly associated with misuse of the MDI with spacer, Respimat, and Breezhaler.

The incidence of COPD increases with age, and COPD is more common in men than in women. ${ }^{18}$ Additionally, risk factors for incorrect inhaler techniques include older age. ${ }^{9}$ However, there are inconsistent results with regard to whether age is related to the incorrect use of inhalers. ${ }^{9,19,20}$ Öztürk et $\mathrm{al}^{20}$ demonstrated that handling errors were especially common in the older group ( $\geq 65$ years). The mean age of the patients enrolled in the current study was $72.10 \pm 8.98$ years, and age was not associated with incorrect inhaler techniques (Tables 2 and 4). Because the dominant population of patients $(65.10 \%)$ was $\geq 70$ years and the age distributions between the pass and misuse groups were similar, the age effect might not be critical in participants $\geq 70$ years.

Previous studies demonstrated that the proportion of patients who used the MDI incorrectly was higher than the proportions of patients using other inhalers. ${ }^{21,22}$ Moreover, a study by Ganguly et al showed that the higher proportion of users of MDI with spacer handle the device correctly (20.80\%), compared with MDI users $(6.00 \%)$ and dry power inhaler (DPI) users $(16.12 \%) .{ }^{23}$ However, those studies did not include Respimat. Our study included Respimat, and found that its misuse rate was highest (87.89\%) across the five inhaler types (Table 2). Similarly, Molimard et $\mathrm{al}^{24}$ demonstrated that the handling error with Respimat was higher than in the other four inhalers. Moreover, the incorrect rate in the "assemble the inhaler" step was particularly high when Respimat was used (62.78\%, Table 3). These results indicate that Respimat is an inhaler whose use needs to be carefully learned - especially the step of assembling the inhaler. Health education providers should help patients confirm the accuracy of this step for Respimat. Additionally, our study found that the step "breathe out fully" had the most errors across all types of inhalers. Lee et a $\mathrm{a}^{19}$ evaluated the inhaler techniques of patients with COPD in South Korea with similar age (66.8 \pm 8.2$)$ and gender distributions (male: $91.8 \%$ ) to that of the study population in the present study. Their results also demonstrated that the highest incorrect frequency occurred in the "breathe out fully" step. Failing to perform this step correctly decreased 
Table 4 Logistic regression analysis of the patient characteristics associated with inhaler misuse

\begin{tabular}{|c|c|c|c|c|}
\hline & \multicolumn{2}{|l|}{ MDI with spacer } & \multicolumn{2}{|l|}{ Diskus $^{\circledR}$} \\
\hline & COR $(95 \% \mathrm{Cl})$ & aOR $(95 \% \mathrm{Cl})$ & cOR $(95 \% \mathrm{Cl})$ & aOR $(95 \% \mathrm{CI})$ \\
\hline Age & $1.03(0.98-1.09)$ & $1.05(0.96-1.15)$ & $1.03(0.93-1.13)$ & $1.14(0.03-48.21)$ \\
\hline Female (vs male) & $1.52(0.17-13.89)$ & $4.32(0.20-92.88)$ & $>999.9(<0.0 \mathrm{I}->999.9)$ & $|0.2|(<0.0 \mid->999.9)$ \\
\hline BMI & $1.05(0.93-1.20)$ & $1.05(0.89-1.25)$ & $0.79(0.59-1.06)$ & $0.26(<0.0 \mathrm{I}->999.9)$ \\
\hline \multicolumn{5}{|l|}{ Educational level } \\
\hline $\begin{array}{l}\text { Higher than junior high school } \\
\text { (vs illiterate and elementary school) }\end{array}$ & $1.09(0.34-3.50)$ & $1.73(0.29-10.17)$ & $0.38(0.05-2.77)$ & $>999.9(<0.01->999.9)$ \\
\hline \multicolumn{5}{|l|}{ Hearing } \\
\hline Poor (vs good) & $7.74(1.64-36.60)$ & $9.85(1.40-69.30)$ & $2.78(0.25-30.91)$ & $>999.9(<0.01->999.9)$ \\
\hline \multicolumn{5}{|l|}{ Eyesight } \\
\hline Poor (vs good) & $1.32(0.46-3.83)$ & $0.66(0.13-3.46)$ & $2.50(0.35-18.04)$ & $>999.9(<0.01->999.9)$ \\
\hline Sedative agents & $0.87(0.16-4.75)$ & $0.49(0.07-3.69)$ & $<0.01(<0.01->999.9)$ & $<0.0 \mathrm{I}(<0.0 \mathrm{I}->999.9)$ \\
\hline Number of acute exacerbations & $0.77(0.42-1.4 \mid)$ & $0.62(0.26-1.48)$ & $1.36(0.11-16.58)$ & $>999.99(<0.01->999.9)$ \\
\hline Number of inhalers used $<2$ (vs $\geq 2$ ) & $0.94(0.33-2.7 I)$ & $2.30(0.5 I-10.32)$ & $1.33(0.20-9.08)$ & $>999.99(<0.01->999.9)$ \\
\hline Duration of inhaler use (months) & $1.05(0.99-1.11)$ & $1.03(0.96-1.11)$ & $1.02(0.97-1.08)$ & $1.65(0.15-18.44)$ \\
\hline \multicolumn{5}{|l|}{ Inhaler-related knowledge } \\
\hline Incorrect (vs correct) & $6.42(2.06-20.04)$ & $9.58(2.14-42.80)$ & $3.75(0.34-41.08)$ & $>999.99(<0.01->999.9)$ \\
\hline
\end{tabular}

Notes: The number of acute exacerbation was investigated over the preceding 3 months. The association between the patient characteristics and misuse was calculated using a logistic regression model.

Abbreviations: BMI, body mass index; MDI, metered-dose inhaler; cOR, crude odds ratio; aOR, adjusted odds ratio; $\mathrm{Cl}$, confidence interval.

the patient's ability to take a full breath and affected the delivery of the inhaled medication. Additionally, a relatively high rate of errors occurred in the step "hold breath" in the study, which was consistent with the results of the previous study. ${ }^{8}$

A lower education level did not increase the misuse rate of handling inhalers in the present study, which was in agreement with the findings of the study by Lee et al. ${ }^{19}$ Melani et $\mathrm{al}^{8}$ revealed that errors in the critical steps were reduced in patients with a higher degree of education, but that study included patients with COPD as well as those with asthma. Therefore, whether the characteristics of patients with asthma influenced the results is unclear. Our findings showed that poor vision was not significantly associated with incorrect inhaler techniques (Tables 2 and 4). However, a previous study found that poor vision was associated with Diskus misuse but it did not find significant associations between poor vision and MDI misuse. ${ }^{5}$ The authors described other device-specific unmeasured confounders that might be responsible for incorrect inhaler techniques and may need to be evaluated further. Moreover, we found that poor hearing and the number of acute exacerbations were specifically related to misuse of the MDI with spacer and Breezhaler (Table 4), respectively. Thus, other device-specific factors could have influenced these results.

Incorrect inhaler-related knowledge significantly increased the possibilities of misuse of the MDI with spacer, Respimat, and Breezhaler (Table 4). This finding emphasizes the importance of patients' inhaler-related knowledge. Therefore, health education providers should provide professional information about the various types of inhalers and confirm patients' knowledge about their inhalers.

This study has some limitations. The sample size of patients handling the Diskus and Turbuhaler inhalers was small. Therefore, large-scale studies are needed to verify the results. Moreover, neither well-trained health education providers nor standardized educational guidelines were available to undertake the inhaler education, which could have led to inhaler misuse by the patients. Therefore, health education providers should be trained to be professional and responsible when applying standardized patient education guidelines. Despite these limitations, this study provides the first data regarding the misuse of different types of inhalers in Taiwan.

\section{Conclusion}

These data provide an overview of inhaler misuse and are helpful in devising a strategy to decrease inhaler use errors. Based on the current study, educational interventions should be designed to correct individual errors in inhaler technique.

\section{Acknowledgment}

The authors highly appreciate Ms Chiu-Wan Liu for her considerable assistance in the collection of data.

\section{Disclosure}

The authors report no conflicts of interest in this work. 


\begin{tabular}{|c|c|c|c|c|c|}
\hline \multicolumn{2}{|l|}{ Turbuhaler ${ }^{\circledR}$} & \multicolumn{2}{|l|}{ Respimat $^{\circledR}$} & \multicolumn{2}{|l|}{ Breezhaler $^{\circledR}$} \\
\hline COR $(95 \% \mathrm{Cl})$ & aOR $(95 \% \mathrm{Cl})$ & cOR $(95 \% \mathrm{Cl})$ & aOR $(95 \% \mathrm{Cl})$ & cOR $(95 \% \mathrm{Cl})$ & aOR $(95 \% \mathrm{Cl})$ \\
\hline $1.02(0.92-1.12)$ & $0.16(<0.01->999.9)$ & $1.03(0.99-1.08)$ & $1.02(0.96-1.08)$ & $1.03(0.98-1.08)$ & $\mathrm{I} .04(0.97-\mathrm{I} . \mathrm{II})$ \\
\hline$>999.9(<0.01->999.9)$ & $<0.01 \quad(<0.01->999.9)$ & $0.68(0.08-6.06)$ & $0.68(0.06-7.43)$ & $1.08(0.09-12.33)$ & $0.13(<0.01-128.95)$ \\
\hline I.05 (0.79-I.40) & $12.63(<0.01->999.9)$ & $0.98(0.88-1.08)$ & $0.99(0.88-1.12)$ & $1.00(0.90-1.11)$ & $1.02(0.89-1.15)$ \\
\hline $0.14(0.01-1.68)$ & $<0.01 \quad(<0.01->999.9)$ & $1.26(0.48-3.30)$ & $2.03(0.70-6.02)$ & $1.02(0.40-2.62)$ & $1.22(0.35-4.27)$ \\
\hline$>999.9(<0.01->999.9)$ & $>999.9(<0.01->999.9)$ & $2.23(0.8 I-6.17)$ & $1.55(0.49-4.88)$ & I.II (0.45-2.74) & $0.78(0.21-2.97)$ \\
\hline $1.13(0.13-9.94)$ & $>999.9(<0.01->999.9)$ & $1.32(0.59-2.97)$ & $1.30(0.50-3.40)$ & $1.20(0.52-2.77)$ & $0.90(0.27-2.95)$ \\
\hline $0.40(0.03-5.96)$ & $<0.01 \quad(<0.01->999.9)$ & $1.91(0.43-8.55)$ & $1.30(0.27-6.28)$ & $1.94(0.25-3.44)$ & $0.800(0.15-4.21)$ \\
\hline $0.64(0.05-8.5 I)$ & $<0.01 \quad(<0.01->999.9)$ & $1.22(0.59-2.52)$ & $1.36(0.55-3.38)$ & $2.97(1.27-6.85)$ & $4.07(1.50-11.08)$ \\
\hline $0.55(0.06-4.91)$ & $>999.9(<0.01->999.9)$ & $0.73(0.31-1.70)$ & $0.65(0.25-1.68)$ & $1.14(0.38-3.44)$ & $1.65(0.37-7.43)$ \\
\hline $0.99(0.95-1.03)$ & $0.77(0.04-15.88)$ & $1.02(0.97-1.08)$ & $1.02(0.96-1.08)$ & $1.21(0.96-1.51)$ & $1.33(0.99-1.78)$ \\
\hline$>999.9(<0.01->999.9)$ & $>999.9(<0.0 \mathrm{I}->999.9)$ & $4.79(|.99-| 1.5 \mid)$ & $5.14(2.07-12.76)$ & $5.87(1.86-18.55)$ & $6.98(1.95-25.08)$ \\
\hline
\end{tabular}

\section{References}

1. Mannino DM, Buist AS. Global burden of COPD: risk factors, prevalence, and future trends. Lancet. 2007;370(9589):765-773.

2. Chapman KR, Mannino DM, Soriano JB, et al. Epidemiology and costs of chronic obstructive pulmonary disease. Eur Respir J. 2006;27(1): 188-207.

3. Chan TC, Wang HW, Tseng TJ, Chiang PH. Spatial clustering and local risk factors of chronic obstructive pulmonary disease (COPD). Int J Environ Res Public Health. 2015;12(12):15716-15727.

4. Komase Y, Asako A, Kobayashi A, Sharma R. Ease-of-use preference for the ELLIPTA ${ }^{\circledR}$ dry powder inhaler over a commonly used single-dose capsule dry powder inhaler by inhalation device-naive Japanese volunteers aged 40 years or older. Int J Chron Obstruct Pulmon Dis. 2014;9:1365-1375.

5. Press VG, Arora VM, Shah LM, et al. Misuse of respiratory inhalers in hospitalized patients with asthma or COPD. J Gen Intern Med. 2011; 26(6):635-642.

6. Lavorini F, Magnan A, Dubus JC, et al. Effect of incorrect use of dry power inhalers on management of patients with asthma and COPD Respir Med. 2008;102(4):593-604.

7. Cochrane MG, Bala MV, Downs KE, Mauskopf J, Ben-Joseph RH. Inhaled corticosteroids for asthma therapy: patient compliance, devices, and inhalation technique. Chest. 2000;117(2):542-550.

8. Melani AS, Bonavia M, Cilenti V, et al; Gruppo Educazionale Associazione Italiana Pneumologi Ospedalieri. Inhaler mishandling remains common in real life and is associated with reduced disease control Respir Med. 2011;105(6):930-938.

9. Wieshammer S, Dreyhaupt J. Dry powder inhalers: which factors determine the frequency of handling errors? Respiration. 2008;75(1):18-25.

10. van der Palen J, Klein JJ, van Herwaarden CL, Zielhuis GA, Seydel ER. Multiple inhalers confuse asthma patients. Eur Respir J. 1999;14(5): 1034-1037.

11. Williams MV, Baker DW, Honig EG, Lee TM, Nowlan A. Inadequate literacy is a barrier to asthma knowledge and self-care. Chest. 1998; 114(4):1008-1015.

12. Lin CW, Chen YY, Chen YJ, Liang CY, Lin MS, Chen W. Prevalence, risk factors, and health-related quality of life of osteoporosis in patients with COPD at a community hospital in Taiwan. Int J Chron Obstruct Pulmon Dis. 2015;10:1493-1500.
13. Batterink J, Dahri K, Aulakh A, Rempel C. Evaluation of the use of inhaled medications by hospital inpatients with chronic obstructive pulmonary disease. Can J Hosp Pharm. 2012;65(2):111-118.

14. Dekhuijzen PN, Lavorini F, Usmani OS. Patients' perspectives and preferences in the choice of inhalers: the case for Respimat ${ }^{\mathbb{}}$ or HandiHaler $^{\circledR}$. Patient Prefer Adherence. 2016;10:1561-1572.

15. van der Palen J, Thomas M, Chrystyn H, et al. A randomised open-label cross-over study of inhaler errors, preference and time to achieve correct inhaler use in patients with COPD or asthma: comparison of ELLIPTA with other inhaler devices. NPJ Prim Care Respir Med. 2016;26:16079.

16. Qureshi H, Sharafkhaneh A, Hanania NA. Chronic obstructive pulmonary disease exacerbations: latest evidence and clinical implications. Ther Adv Chronic Dis. 2014;5(5):212-227.

17. Cheng SL, Chan MC, Wang CC, et al. COPD in Taiwan: a National Epidemiology Survey. Int J Chron Obstruct Pulmon Dis. 2015;10: 2459-2467.

18. Afonso AS, Verhamme KM, Sturkenboom MC, Brusselle GG. COPD in the general population: prevalence, incidence and survival. Respir Med. 2011;105(12):1872-1884.

19. Lee H, Boo S, Lim Y, Kim S, Kim IA. Accuracy of inhaler use in patients with chronic obstructive pulmonary disease. Clin Nurs Res. 2014; 23(5):560-574.

20. Öztürk C, Kaya A, Bilgin C, et al. Evaluation of inhaler technique and patient satisfaction with fixed-combination budesonide/formoterol drypowder inhaler in chronic obstructive pulmonary disease (COPD): data on real-life clinical practice in Turkey. Tuberk Toraks. 2012;60(4):301-313.

21. Molimard M, Raherison C, Lignot S, Depont F, Abouelfath A, Moore N. Assessment of handling of inhaler devices in real life: an observational study in 3811 patients in primary care. $J$ Aerosol Med. 2003;16(3):249-254.

22. Dahl R, Backer V, Ollgaard B, Gerken F, Kesten S. Assessment of patient performance of the HandiHaler compared with the metered dose inhaler four weeks after instruction. Respir Med. 2003;97(10):1126-1133.

23. Ganguly A, Das AK, Roy A, et al. Study of proper use of inhalational devices by bronchial asthma or COPD patients attending a tertiary care hospital. J Clin Diagn Res. 2014;8(10):HC04-7.

24. Molimard M, Raherison C, Lignot S, et al. Chronic obstructive pulmonary disease exacerbation and inhaler device handling: real-life assessment of 2935 patients. Eur Respir J. 2017;49(2):pii: 1601794. 


\section{Publish your work in this journal}

The International Journal of COPD is an international, peer-reviewed journal of therapeutics and pharmacology focusing on concise rapid reporting of clinical studies and reviews in COPD. Special focus is given to the pathophysiological processes underlying the disease, intervention programs, patient focused education, and self management protocols.

This journal is indexed on PubMed Central, MedLine and CAS. The manuscript management system is completely online and includes a very quick and fair peer-review system, which is all easy to use. Visit http://www.dovepress.com/testimonials.php to read real quotes from published authors.

Submit your manuscript here: http://www.dovepress.com/international-journal-of-chronic-obstructive-pulmonary-disease-journal 